\title{
A tool for general quality assessment of black tea - retail price prediction by an electronic tongue
}

Maria Khaydukova ${ }^{\mathrm{a}, \mathrm{b}}$, Xavier Cetóc, Dmitry Kirsanov ${ }^{\mathrm{a}, \mathrm{b}}$, Manel del Valle ${ }^{\mathrm{c}}$, Andrey Legin ${ }^{\mathrm{a}, \mathrm{b}}$

${ }^{a}$ Laboratory of Chemical Sensors, St. Petersburg State University, 7-9, Universitetskaya nab.,199034, St.Petersburg, Russia

${ }^{b}$ Laboratory of Artificial Sensory Systems, ITMO University, 49, Kronverkskiy pr., 197101, St.Petersburg, Russia

${ }^{c}$ Sensors \& Biosensors Group, Department of Chemistry, Universitat Autònoma de Barcelona, Edifici Cn, 08193 Bellaterra, Spain

$+78123282835$

$+78123282835$

e-mail: khaydukova.m@gmail.com

Article Note:

\section{Abstract}

Retail price of food products is a complex interplay between multiple factors. Overall product quality has got one of the most serious impacts on the price in many situations. In the present study an artificial sensory system (potentiometric electronic tongue) was employed for the analysis of black tea samples purchased in the retail stores in Spain and Russia. It was possible to relate the response of a potentiometric sensor system formed by 22 ion-selective electrodes with retail prices of various black tea samples by means of partial least squares regression. PLS regression models allowed for prediction of retail price with mean relative errors of about $15 \%$ and $25 \%$ for Spain's tea bags and for loose packed tea from Russia, respectively. The suggested approach shows a good promise for the development of an instrumental analytical technique for regulatory authorities to fight with counterfeits, and for commercial purposes to evaluate market space.

Keywords: black tea, multisensor system, electronic tongue, retail price assessment

\section{Introduction}

Tea is a beverage widely consumed throughout the world. Green, Oolong and Black - these are three general types of manufactured tea, which are unfermented, partially and fully fermented tea respectively (Harbowy et al. 1997'). Tea's brews have got very complicated chemical composition. Numerous sophisticated analytical techniques are used for individual component determination and the most popular are epyvarieties of high performance liquid chromatography and capillary electrophoresis (Sang et al. 2011 $1^{\text {ii }}$ Z Zhao at al. 2013 ${ }^{\text {iii }}$ ). These (an many other) methods can provide 
important information about component's content, but they are poorly relevant for assessment of global tea quality. This task is usually accomplished by evaluation of human derived flavour parameters. In the case of tea, which is mostly being sold at the world tea auctions, the cost of the product is directly related to its quality, taste and flavour characteristics that are estimated by human sensory panels. Market customers generally suppose that retail price is a function of products quality. In most cases it is true, but it might be rather hard to confirm it without special knowledge and skills. One of the possible ways to circumvent this hindrance is to use artificial sensory systems for price estimation, and likely for possible counterfeit identification. In previous research studies, different types of multisensor systems were suggested for evaluation of flavour descriptors in beers (Rudnitskaya et al. 2009 $;^{\text {iv }}$ ), wines (Legin et al. 2003 ${ }^{\mathrm{v}}$; Kang et al. 2013 ${ }^{\mathrm{vi}}$ ), brandies (Cetó et al. 2013 $3^{\text {vii }}$ ), pharmaceuticals (Eckert et al. 2014 ${ }^{\text {viii)}}$ ), etc. It was found that sensor's responses of such systems are well correlated with human taste and flavour descriptors such as bitterness, sourness, sweetness and etc.

Chemical sensors are very attractive analytical instrument due to simplicity and rapidity of the application and affordable analysis prices. Along with discrete sensors, quite useful for certain applications (Meyerhoff et al. $1986^{\mathrm{ix}}$ ), there is another approach widely called now "electronic tongue" (ET). ET is an analytical instrument comprising an array of cross-sensitive sensors, an appropriate data acquisition system for sensors response recording and multivariate data processing engine (Legin et al. 1997 ${ }^{\mathrm{x}}$ ). Multisensor systems are able to produce qualitative or quantitative integral information about complex analysed media (del Valle 2010 $0^{\mathrm{xi}}$ ). Chemometric techniques such as principal component analysis (PCA) (Laddi et al. 2014 ${ }^{\mathrm{xii}}$ ), linear discrimination analysis (LDA) (Bhattacharyya et al. 2014 ${ }^{\text {xiii }}$ ) or partial least squares discriminant analysis (PLSDA) (Avula et al. 2014 ${ }^{\mathrm{xiv}}$ ) could be used in the cases of classification. For quantitative analysis and prediction of the particular properties of the samples PLS (Chen et al. $2006^{\mathrm{xV}}$ ) or artificial neural networks (ANN) (Chosh et al. 2012 $2^{\mathrm{xvi}}$ ) are two of the most applied strategies.

It was demonstrated that various types of multisensor systems could be employed for tea analysis. Such systems are able to classify the tea samples according to their quality (Bhattacharyya et al. 2014), identify the samples of different geographical origin (He et al. 2009 ${ }^{\text {xvii }}$ ), partially determine tea chemical contents (Chen et al. 2010 ${ }^{\text {xiiii) }}$ ) and evaluate tea types (Gallardo et al. 2005 ${ }^{\text {xix }}$, Liu et al. $\left.2014^{\mathrm{xx}}\right)$. Furthermore, it was shown that the response of an ET system can be highly correlated with specific sensory attributes and had a potential to predict these attribute in tea samples (He et al. 2009). The capability of a multisensor system for tea grade evaluation was also demonstrated (Chen et al. 2008 ${ }^{\mathrm{xxi}}$ ).

The most interesting applications of multisensor systems are related to the evaluation of parameters having complex integral nature that are not directly correlated with the content of certain chemical substances in the sample. In the present work we suggest using an artificial sensory system for estimation of the tea retail price. 


\section{Materials and Methods}

\section{Samples}

A total of 34 black tea samples were analysed in this study. The samples were bought in retail stores in Spain and Russia. The sample set included: 19 samples of tea bags (13 from Russia, 6 from Spain), 8 samples of loose packed tea (all from Russia) and 7 samples of tea sold by weight in specialized stores (4 from Spain, 3 from Russia). Price range was from 3 to 283 Euros per $\mathrm{kg}$. Prices of samples bought in Russia were converted into Euros at exchange rate of June 2013.

\section{Sample preparation}

The procedure of tea sample preparation was as follows: $2 \mathrm{~g}$ of dry tea were brewed in $100 \mathrm{ml}$ of freshly boiled distilled water during $5 \pm 0.1 \mathrm{~min}$. Afterwards, the sample was filtered using filter paper and the solution was cooled down on an ice-bath to $25 \pm 1{ }^{\circ} \mathrm{C}$. Then $30 \mathrm{ml}$ of the broth were diluted with $70 \mathrm{ml}$ of distilled water and this liquid was used for measurement. Since the tea properties depend on the temperature and brew's lifespan it was vitally important providing for the identical experimental conditions so that sample's preparation procedures and chronology were closely similar in all cases.

\section{Artificial sensory system}

A multisensor system was comprised of an array of cross-sensitive sensors, the 32-channel digital high impedance voltmeter and PC for data acquisition. The array included 22 chemical sensors, 10 of which were anion-sensitive polyvinylchloride (PVC) plasticized ion-selective electrodes (ISEs), 8 cation-sensitive PVC - plasticized ISEs, 3 chalcogenide glass sensors with red/ox sensitivity and one standard $\mathrm{pH}$ glass electrode. Electromotive force values were measured against the standard $\mathrm{Ag} / \mathrm{AgCl}$ reference electrode with $0.1 \mathrm{mV}$ precision.

Electrochemical measurements were carried out in the following galvanic cell:

$\mathrm{Cu}|\mathrm{Ag}| \underline{\mathrm{AgCl}}, \mathrm{KCl} \mid$ sample solution | membrane | solid inner contact $\mid \mathrm{Cu}$

All tea samples were measured at least in 4 replicas in random order. The measurement time in each sample was $3 \mathrm{~min}$. After each sample measurement, the sensors array was washed 3 times with distilled water. The total wash cycle duration was 9 minutes, which allowed sensors' potential to get back to the initial readings in water.

\section{Data processing}

The relationship between the sensor system's responses and the price of black teas was studied by PLS regression. Detailed information about this technique could be found in literature (Esbensen $\left.2001^{x \times i i}\right)$. Sensor responses were averaged over 4 replicas. Mean values were included into the data matrix, which size was 35 (samples) x 22 (sensors). Samples prices were recalculated per kilo of the tea and these values were used as reference ones. PLS models were computed using The Unscrambler ${ }^{\circledR} 9.7$ (CAMO Software AS, Norway). 


\section{Results and Discussion}

As the first step, a PLS model was built for the data set containing sensor responses in all tea samples. Interrelation between sensors responses and reference data can be roughly estimated with the squared correlation coefficient $\left(R^{2}\right)$. The resulted $R^{2}$ for the first model was 0.07 . This value suggests that there is no relationship between the sensor array response and the price. This result can be explained taking into account the way of pricing. Retail price includes the costs of the wholesale purchase, delivery, customs duties, taxes and charges. Russia and Spain are situated in the different geographic regions that assume different transportation costs. Customs duties and taxes differ too in different countries. Thereby individual model should be likely calculated for each country. Fig. 1 deals with PCA score plot for the ET data in all tea samples. This plot is a map of samples, where similar samples are placed close to each other while the samples while those different in overall chemical composition located far from each other. It can be seen on Fig. 1 that the samples are split into two groups according to packing type. Teas in bags are located on the right side and the other types of teas on the left side of the score plot. One of the possible reasons for the splitting is that the quality of tea leaves in the bags could be lower than those of loose tea (Cao te al. 2006 ${ }^{\text {xiiii }}$ ). This was shown earlier by comparing the fluoride levels correlated with concentration of polyphenols and amino acids, which are largely responsible for tea quality (Lu et al. 2004 $4^{\text {xxiv }}$ ). The cost of tea bag additionally includes an extra outlay for pre-packing and packing. Therefore, it is better building a model for each type of tea from each country separately. It was impossible to do this kind of modeling for the teas with the highest prices since there were only 4 samples from Russia and 3 from Spain. Therefore only three PLS models were constructed, for tea bags from both countries and for loose tea from Russia. Due to a small number of samples in the subsets there was no opportunity to split them into calibration and test sets therefore fullcross validations (FCV) were employed for the verification of the models performance. The parameters of resulted PLS models are presented in Table 1. 
Fig. 1. PCA score plot for the ET data in all tea samples (first and second principal components)

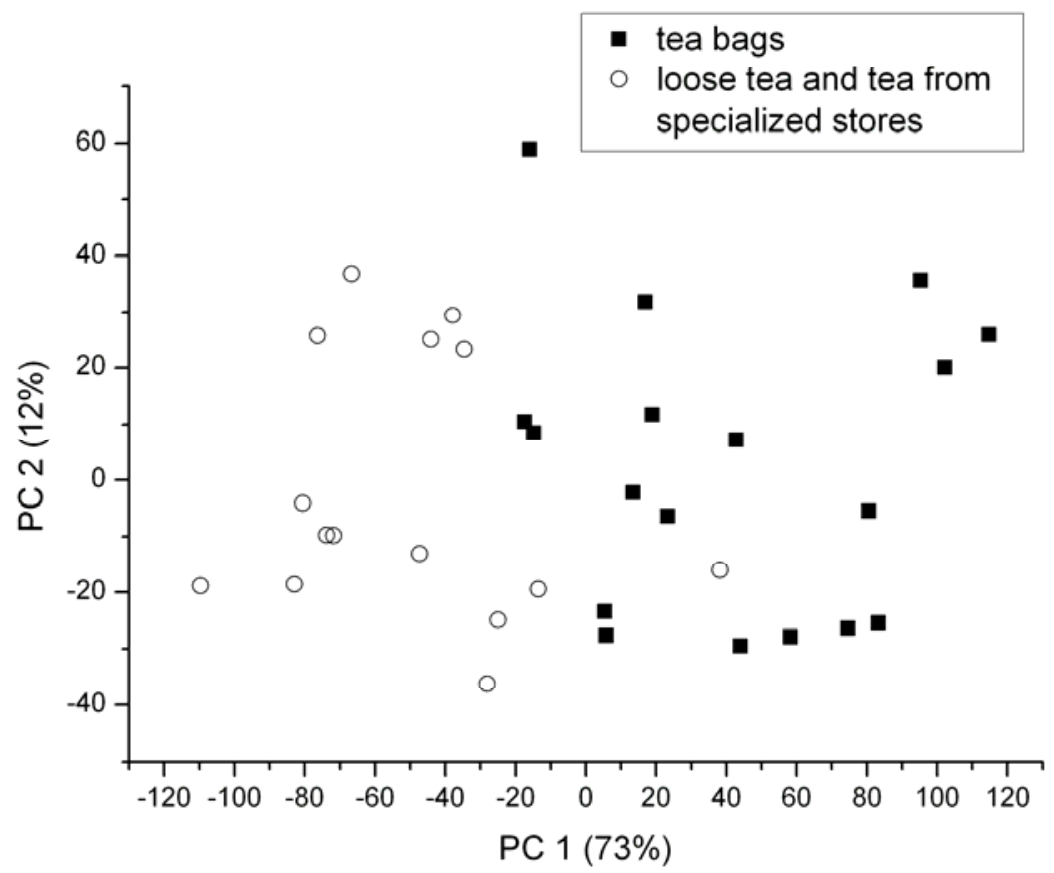

The PLS model for the subset of tea bags bought in Russian shops was not capable of price prediction. One of the possible ways to explain this phenomenon is that the costs for packaging, advertising and other related expenses are relatively high and they significantly eliminate the impact of the raw material prices. On the other hand, the correlation coefficients for the other subsets were close to unity and other characteristics were promising. Root-mean square error of prediction (RMSEP) was calculated in the price units. The artificial sensory system was able predicting the retail price of the loose packed tea with the errors around \pm 4.6 Euro per kg. Price range for this tea type was from 2.8 to 52.0 Euro per $\mathrm{kg}$ and the mean relative error (MRE) thus was $15 \%$. The resulted MRE was found being $25 \%$ for Spanish tea bags with retail price span 1144 Euro per $\mathrm{kg}$. The errors in both cases were rather significant, but it could be the consequence of the comparatively small size of calibration sets and various factors involved in the tea pricing. At the same time the correlation coefficients were highly significant $\left(R^{2}>0.96\right)$. Taking into account a very unusual task formulation, this result can be considered as quite promising for regulating authorities. Application of an artificial sensory system may help detecting counterfeits in a fast and simple way. It must be pointed out that further studies with extended set of samples are required for thorough evaluation of possible limitations of the approach. Also, this procedure, used as diagnostic tool may be useful for commercial purposes to evaluate market space. From this kind of information, it could be visualized if the different brands are correctly positioned in the market, or, as a second example, a new brand might evaluate its potential prize in a certain market. 
Table 1. Parameters of the PLS models for full cross-validation

\begin{tabular}{llllll} 
& Slope & Offset & $\begin{array}{l}\text { RMSEP, } \\
\text { euro }\end{array}$ & $\mathrm{R}^{2}$ & \#V \\
\hline $\begin{array}{l}\text { Tea bags, Russia } \\
\text { (13 samples) }\end{array}$ & 0.26 & 17.7 & 15.4 & -0.01 & 4 \\
\hline $\begin{array}{l}\text { Tea bags, Spain } \\
\text { (8 samples) }\end{array}$ & 0.91 & 2.5 & 3.2 & 0.96 & 4 \\
\hline $\begin{array}{l}\text { Loose tea, Russia } \\
\text { (6 samples) }\end{array}$ & 0.89 & 2.6 & 4.6 & 0.96 & 4 \\
\hline
\end{tabular}

\section{Conclusion}

An artificial sensory system is suggested as a tool for global quality assessment of black teas in terms of their retail price. In spite of a very unusual formulation of the task this type of analysis can be of high interest since it returns the estimate of global quality in a way, which is clear and well understood at the mundane level. PLS modelling of the ET response allowed for prediction of retail price with a reasonable precision of 15-25\%. This promising result was obtained despite the fact that there are numerous other factors influencing the price and they can be not related to the chemical composition of the samples at all. The results show a perspective of the development of an analytical instrument for fast and simple counterfeit detection in the tea market. Its use might also be considered as the current trend of examining the available 'big data' information sets, in this case, originated from sensors, in order to extract new trends or predict consumers' behaviour.

\section{Acknowledgments}

Maria Khaydukova acknowledges St. Petersburg State University for a research grant 12.42.213.2013 and partial financial support from Government of Russian Federation, Grant 074U01. Dmitry Kirsanov and Andrey Legin have received partial financial support from Government of Russian Federation, Grant 074-U0. Manel del Valle thanks the support from the program ICREA Academia.

\section{Conflict of Interest}

Maria Khaydukova declares that she has no conflict of interest. Xavier Cetó declares that he has no conflict of interest. Dmitry Kirsanov declares that he has no conflict of interest. Manel del Valle declares that he has no conflict of interest. Andrey Legin declares that he has no conflict of interest. This article does not describe any studies with human or animal subjects. 


\section{References}

iHarbowy ME, Balentine DA, Davies AP, Cai Y (1997) Tea Chemistry. CritRev.inPlantSci.16(5):415480.doi:10.1080/07352689709701956

ii Sang S, Lambert JD, Ho C.-T, Yang CS (2011) The chemistry and biotransformation of tea constituents. PharmacolRes. 64: 87- 99.doi:10.1016/j.phrs.2011.02.007

iii Zhao M, Ma Y, Dai L.-I, Zhang D.-I, Li J.-h, Yuan W.-x, Li Y.-I, Zhou H.-j (2013) A High-Performance Liquid Chromatographic Method for Simultaneous Determination of 21 Free Amino Acids in Tea. Food Anal.Methods. 6:69-75.doi:10.1007/s12161-012-9408-4

${ }^{\text {iv }}$ Rudnitskaya A, Polshin E, Kirsanov D, Lammertyn J, Nicolai B, Saison D, Delvaux FR, Delvaux F, Legin A (2009) Instrumental measurement of beer taste attributes using an electronic tongue. Anal ChimicaActa. 646: 111-118.doi:10.1016/j.aca.2009.05.008

vLeginA, Rudnitskaya A, Lvova L, Vlasov Yu, Di Natale C, D’Amico A (2003) Evaluation of Italian wine by the electronic tongue: recognition, quantitative analysis and correlation with human sensory perception. Anal ChimicaActa. 484:33-44. doi: 10.1016/S0003-2670(03)00301-5

${ }^{\mathrm{vi}}$ Kang B.-S, Lee J.-E, Park H.-J (2014) Electronic tongue-based discrimination of Korean rice wines (makgeolli) including prediction of sensory evaluation and instrumental measurements. Food Chem. 151 :317-323.doi:10.1016/j.foodchem.2013.11.084

${ }^{\text {vii }}$ Cetó X, Llobet M, Marco J, del Valle M (2013) Application of an electronic tongue towards the analysis of brandies. Anal Methods. 5: 1120-1129. doi: 10.1039/C2AY26066B

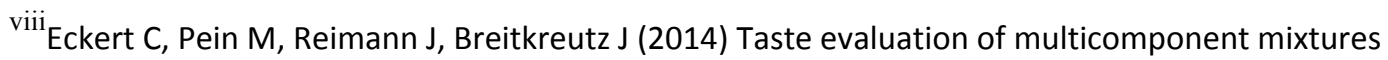
using a human taste panel, electronic taste sensing systems and HPLC. Sens and Actuators B, 182: 294- 299.doi:10.1016/j.snb.2013.03.012

${ }^{\text {ix }}$ Meyerhoff ME, Opdycke WN (1986) Ion-selective electrodes. Adv Clin Chem . 25:1-47.

× Legin A, Rudnitskaya A, Vlasov Yu, Di Natale C, Davide F, D'Amico F (1997) Tasting of beverages using an electronic tongue. Sens and Actuators B. 44:291-296. doi: 10.1016/S09254005(97)00167-6

${ }^{x i}$ del Valle M (2010) Electronic Tongues Employing Electrochemical Sensors. Electroanalysis. 22(14): 1539-1555. doi: 10.1002/elan.201000013

xii Laddi A, Prakash NR, Kumar A (2014) Quality evaluation of black CTC teas based upon seasonal variations. IntJ of Food Sci and Technol. 49:493-500.doi:10.1111/ijfs.12327

xiii Bhattacharyya R, Tudu B, Das SC, Bhattacharyya N, Bandyopadhyay R, Pramanik P (2012) Classification of black tea liquor using cyclic voltammetry. J of Food Eng.109:120126.doi:10.1016/j.jfoodeng.2011.09.026

${ }^{\text {xiv }}$ Avula B, Wang Y.-H, Wang M, Avonto C, Zhao J, Smillie TJ, Rua D, Khan IA (2014) Quantitative determination of phenolic compounds by UHPLC-UV-MS and use of partial least-square discriminant analysis to differentiate chemo-types of Chamomile/Chrysanthemum flower heads. Jof Pharm and Biomed Anal. 88:278-288.doi:10.1016/j.jpba.2013.08.037 
${ }^{\mathrm{xv}}$ Chen Q, Zhao J, Zhang H, Wang X (2006) Feasibility study on qualitative and quantitative analysis in tea by near infrared spectroscopy with multivariate calibration. AnalChimicaActa.752: 77-84. doi:10.1016/j.aca.2006.05.007

${ }^{x v i}$ Ghosh A, Tamuly P, Bhattacharyya N, Tudu B, Gogoi N, Bandyopadhyay R (2012) Estimation of theaflavin content in black tea using electronic tongue. J of Food Eng. 110:71-79.

doi:10.1016/j.jfoodeng.2011.12.007

${ }^{\text {xvii }}$ He W, Hu X, Zhao L, Liao X, Zhang Y, Zhang M, Wu J (2009) Evaluation of Chinese tea by the electronic tongue: Correlation with sensory properties and classification according to geographical origin and grade level. Food Res Int. 42: 1462-

1467.doi:10.1016/j.foodres.2009.08.008

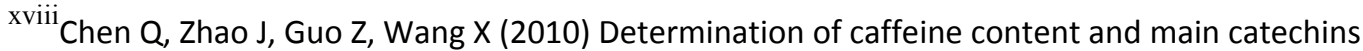
contents in green tea (Camellia sinensis L.) using taste sensor technique and multivariate calibration. J of Food Compos and Anal. 23: 353-358.doi:10.1016/j.jfca.2009.12.010

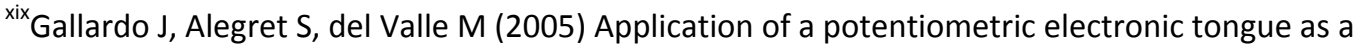
classification tool in food analysis. Talanta. 66:1303-1309. doi: 10.1016/j.talanta.2005.01.049

${ }^{\mathrm{xx}}$ Liu N, Liang Y, Bin J, Zhang Z, Huang J, Shu RX, Yang K (2014) Classification of Greenand Black Teas by PCA and SVM AnalysisofCyclicVoltammetricSignalsfromMetallicOxide-ModifiedElectrode. FoodAnal. Methods. 7:472-480.doi: 10.1007/s12161-013-9649-x

${ }^{x x i}$ Chen Q, Zhao J, Vittayapadung S (2008) Identification of the green tea grade level using electronic tongue and pattern recognition. Food Res Int. 41 : 500504.doi:10.1016/j.foodres.2008.03.005

${ }^{x x i i}$ Esbensen KH (2001) Multivariate Data Analysis - in Practice. An Introduction to Multivariate Data Analysis and Experimental Design, 5th ed., CAMO AS Publ., Oslo

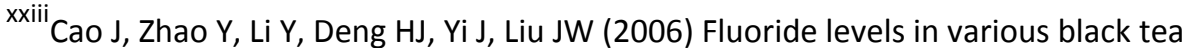
commodities: Measurement and safety evaluation. Food and ChemToxicol. 44:11311137.doi:10.1016/j.fct.2006.01.010

xxiv Lu Y, Guo W.-F, Yang X.-Q (2004)Fluoride Content in Tea and Its Relationship with Tea Quality. J Agric Food Chem. 52:4472-4476.doi:10.1021/jf0308354 